\title{
Avaliação clínica dos procedimentos de expansão cirurgicamente assistida da maxila (ECAM)
}

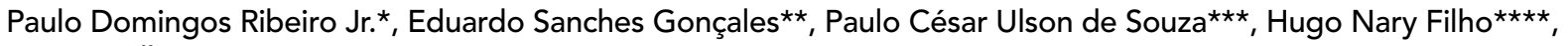
João Gualberto Cerqueira Luz ${ }^{\star \star \star \star \star}$

\section{Resumo}

Objetivo: avaliação clínica dos procedimentos de expansão cirurgicamente assistida da maxila. Metodologia: foram avaliados 10 pacientes tratados através da expansão ortopédica com auxílio cirúrgico, conhecida como expansão cirurgicamente assistida da maxila (ECAM). Avaliou-se a efetividade deste procedimento cirúrgico no auxílio à expansão transversal da maxila proporcionada através de aparelho do tipo Hyrax, a estabilidade desta expansão, as ocorrências pós-operatórias, a quantidade e qualidade da expansão conseguida e alterações estéticas deste procedimento. Resultados e Conclusões: concluiu-se, com um acompanhamento a longo prazo, que a ECAM trata-se de um procedimento eficiente, estável, que proporciona mudanças funcionais e pouca alteração estética facial.

Palavras-chave: Expansão cirurgicamente assistida da maxila. Expansão maxilar. Deficiência transversal da maxila.

\section{INTRODUÇÃO}

Para uma oclusão normal existe a necessidade de que o arco dentário superior guarde dimensões compativelmente maiores que as do arco dentário inferior ${ }^{10}$. Quando estas dimensões forem menores no sentido lateral teremos uma deficiência transversal maxilar, esta pode atingir de 3 a 18\% da população ${ }^{24,47}$.

Na etiologia desta discrepância inclui-se a hereditariedade ${ }^{26}$, injúrias traumáticas iatrogênicas ou não ${ }^{9}$, aberrações de erupção, comprimento inadequado do arco, macroglossia e hábitos para- funcionais ${ }^{42}$.

A atresia maxilar transversal está associada a um comprometimento funcional e estético, como a mordida cruzada posterior bilateral ou unilateral, apinhamentos dentários, obstrução nasal, enurese noturna e a apnéia ${ }^{14,20,42,50}$.

O diagnóstico da deficiência transversal da maxila deve ser estabelecido através do exame clínico, exame radiográfico e estudo dos modelos ${ }^{9}$. A deficiência transversal dentoalveolar da maxila pode ser tratada através de aparelhos ortodônti$\cos ^{10}$. Já as deficiências transversais esqueléticas

\footnotetext{
* Mestre e Doutorando em CTBMF pela UNESP Araçatuba, Professor das disciplinas de Cirurgia e Traumatologia Bucomaxilofacial da Universidade do Sagrado Coração, Bauru-SP.

** Mestre em CTBMF pela PUC-RS, Doutorando em Estomatologia pela FOB-USP - Bauru, Professor das disciplinas de Cirurgia e Traumatologia Bucomaxilofacial da Universidade do Sagrado Coração, Bauru-SP.

*** Ortodontista do Instituto Odontológico de Cirurgia e Prótese de Bauru-SP.

**** Mestre e Doutor em CTBMF pela UNESP Araçatuba, Professor das disciplinas de Cirurgia e Traumatologia Bucomaxilofacial da Universidade do Sagrado Coração, Bauru-SP.

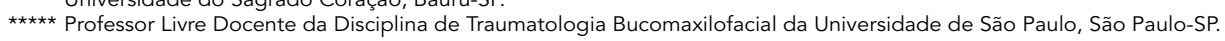


da maxila devem sofrer abordagens terapêuticas que aumentem as dimensões transversais do arco dentário superior, conseguido através da expansão rápida da maxila ortopédica ${ }^{10}$, da ECAM obtida através de osteotomias maxilares e forças ortopédicas e da expansão cirúrgica da maxila através da segmentação desta ${ }^{12,13,29,52}$.

Como se sabe, a expansão rápida da maxila é utilizada com previsibilidade em crianças e adolescentes ${ }^{7,8,10}$, já em pacientes adultos este procedimento apresenta deficiências que podem levar o tratamento a um insucesso ou complicações s, $2,7,12,28,37,53$.

As indicações para a realização da ECAM são quando da ocorrência de falha da expansão ortopédica, quando existir uma deficiência transversal maior que $5 \mathrm{~mm}$ em pacientes fora da fase de crescimento, em pacientes que já adquiriram maturidade esquelética, na existência de problemas periodontais, presença de uma mandíbula larga e em pacientes com idade esquelética de 15 anos ou mais ${ }^{9,48}$.

Os efeitos vantajosos deste tipo de tratamento são conhecidos, entre estes: a manutenção da saúde periodontal, a melhora do fluxo de ar nasal, a eliminação do espaço negativo posterior, evitase exodontias, envolve o mínimo de morbidade e desconforto durante a expansão, além de propiciar alta estabilidade ${ }^{6,41,48,49}$.

Com este trabalho tivemos o objetivo de avaliar através de uma técnica de ECAM a quantidade de expansão maxilar conseguida, a qualidade desta expansão maxilar, morbidades relacionadas a este procedimento, assim como alterações estéticas e funcionais proporcionadas pelo auxílio cirúrgico à expansão maxilar.

\section{MATERIAL E MÉTODO}

Foram avaliados dez pacientes da disciplina de Cirurgia e Traumatologia Bucomaxilofacial da Universidade do Sagrado Coração - Bauru/SP, portadores de deficiência transversal esquelética da maxila. Sendo oito pacientes do gênero femi- nino e dois pacientes do gênero masculino, com idade média de 29 anos e 2 meses (17 anos e 4 meses a 41 anos e 11 meses).

O critério utilizado para indicação do procedimento cirúrgico foi a falha da expansão rápida da maxila ortopédica, a não aceitação do desconforto proporcionado pela expansão ortopédica, a quantidade de expansão requerida, a existência de alterações periodontais, a idade e a maturação esquelética do paciente e o exame físico do paciente (Fig. 1, 2).

O plano de tratamento compreendia a instalação de aparelho expansor do tipo Hyrax para posterior osteotomia maxilar para auxílio da expansão.

As cirurgias foram realizadas sob anestesia geral em nível hospitalar ambulatorial. A técnica cirúrgica utilizada baseou-se em uma incisão junto à mucosa alveolar, desde a região do elemento 16 até a região do 26 , seccionando a região do freio labial. Realizava-se o descolamento muco-periostal, estendendo via submucosa até a região de união dos processos pterigóides com o tuber da maxila (Fig. 3).

A osteotomia realizada compreendeu uma do tipo Le Fort I sub-total, onde os pilares de reforço do esqueleto facial foram seccionados. Iniciava-se sobre o pilar canino, aproximadamente $5 \mathrm{~mm}$ acima do ápice do canino, seguindo paralelamente ao plano oclusal superior no sentido posterior até a região de tuber da maxila. Sendo, desta maneira, necessária uma osteotomia vertical de aproximadamente $6 \mathrm{~mm}$ sobre o pilar zigomático, para que assim o mesmo sentido fosse mantido na região posterior (Fig. 4).

Para união das demarcações foram utilizadas brocas tronco-cônicas número 702 , sobre constante irrigação com soro fisiológico. A osteotomia vertical sobre o pilar zigomático foi realizada numa largura um pouco menor que a metade da expansão desejada. Na região posterior, a osteotomia foi completada com cinzéis retos sob ação de martelos, estendendo até a união do tuber com os 

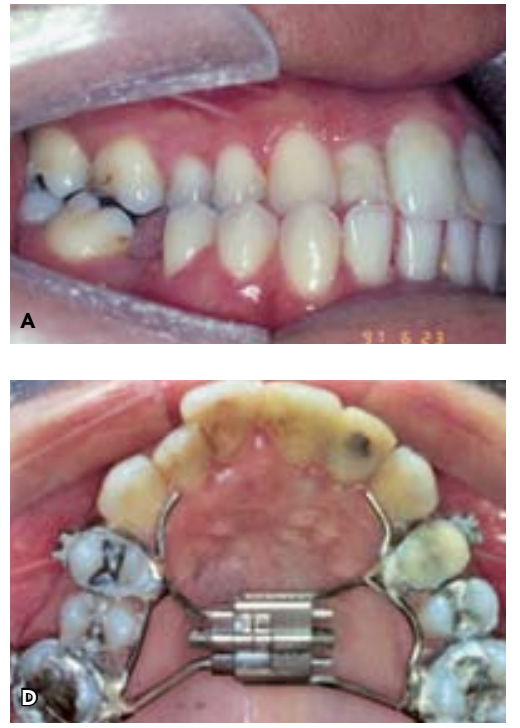

FIGURA 1 - A, B, C) Mordida cruzada posterior bilateral; D) aparelho Hyrax instalado.

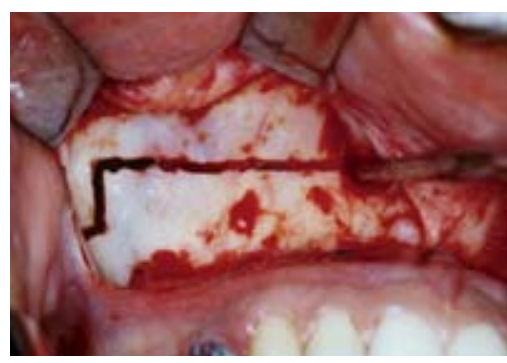

FIGURA 4 - Osteotomia horizontal na maxila paralela ao plano oclusal superior.
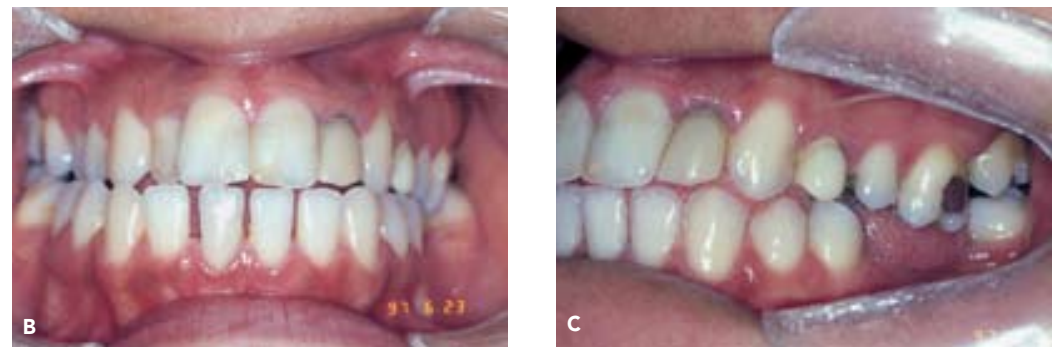

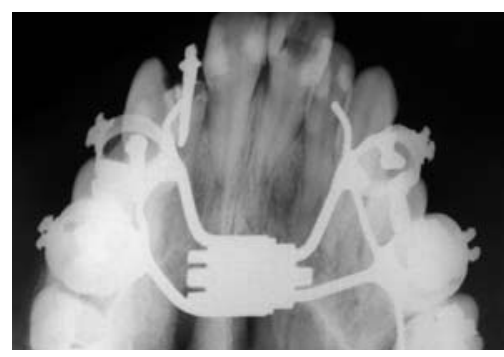

FIGURA 2 - Tomada radiográfica oclusal da maxila pré-operatória.

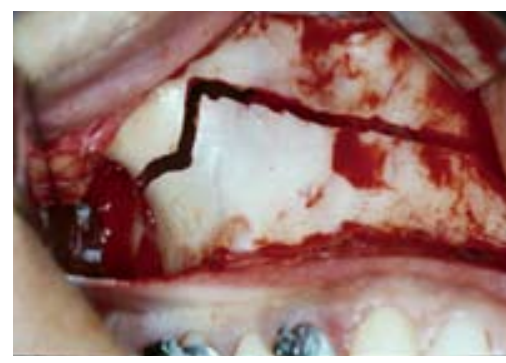

FIGURA 5 - Linha de osteotomia avançando no sentido posterior.

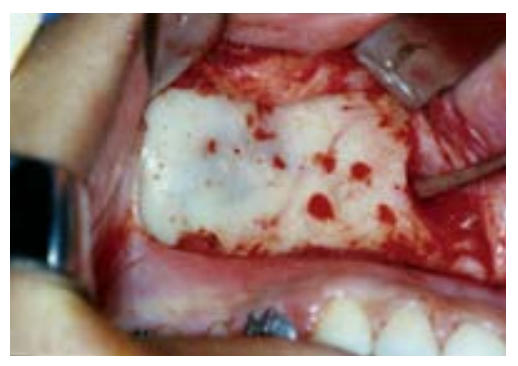

FIGURA 3 - Incisão e descolamento realizados e marcações com brocas na região lateral da maxila.

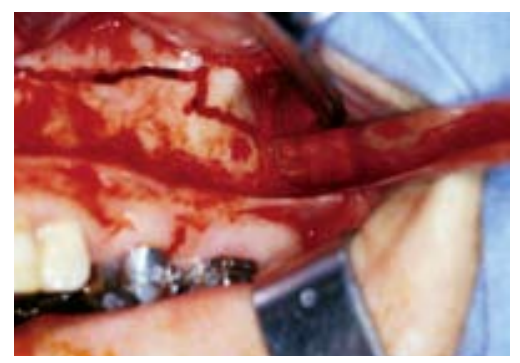

FIGURA 6 - Cinzel curvo posicionado para a osteotomia na região de articulação pterigomaxilar. processos pterigóides (Fig. 5). A osteotomia para liberação dos processos pterigóides do osso esfenóide da maxila foi procedida em todos os casos. Para este fim foram utilizados cinzéis curvos sobre a ação de martelos (Fig. 6).

Posteriormente foi realizada a osteotomia com cinzéis e martelo na porção anterior da parede lateral da cavidade nasal, penetrando com o cinzel no sentido posterior aproximadamente $5 \mathrm{~mm}$, seccionando o pilar canino (Fig. 7). O cinzel foi então posicionado na região interincisiva, primeiramente direcionado para o osso alveolar até que se detectasse a penetração através da tábua óssea palatina do processo alveolar (Fig. 8). Posteriormente direcionou-se o cinzel paralelamente às lâ- minas horizontais do osso palatino e o introduziuse no sentido caudal até o rompimento da sutura intermaxilar. Verificava-se a mobilidade da maxila bilateralmente, na ocorrência de uma mobilidade assimétrica, todas as osteotomias eram revisadas. A ativação do aparelho não foi realizada no transoperatório.

Após cuidados procedia-se a sutura contínua espiralar bilateralmente com fio de poliglactina 910 4-0 (Vicryl 4-0). Posteriormente uma sutura isolada simples unia a região de freio labial correspondente à região mediana. E então, com sutura contínua espiralar, finalizava-se o fechamento da ferida nas regiões de canino à linha média, com o mesmo fio.

Durante o trans-operatório era requisitada 


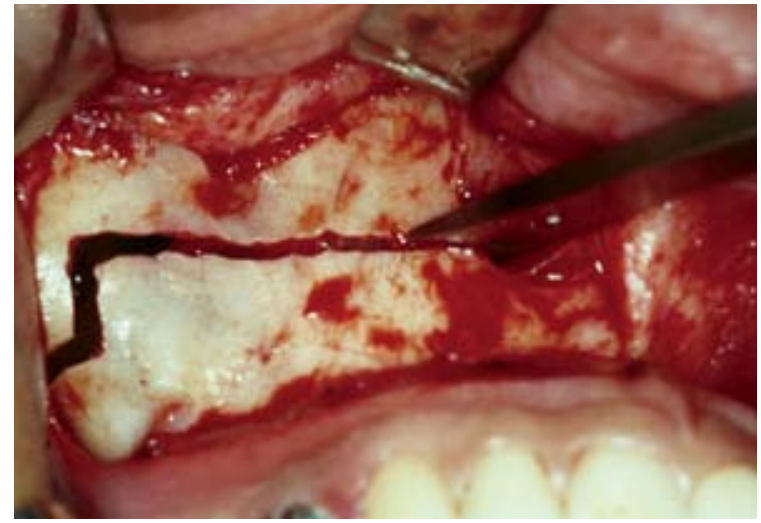

FIGURA 7 - Cinzel posicionado na região de pilar canino.

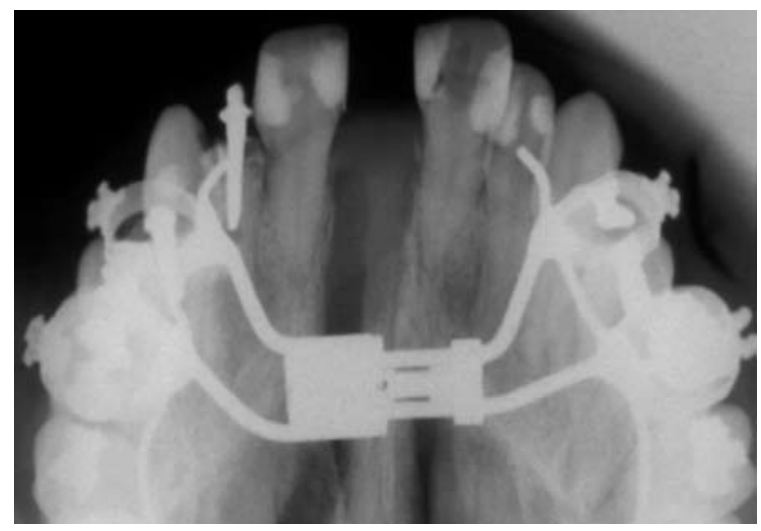

FIGURA 9 - Radiografia oclusal pós-operatória.

a administração de solução de cefalotina $1,0 \mathrm{~g}$ (Keflin 1,0g) e a de corticosteróide (Dexametasona $10 \mathrm{mg}$ ) endovenosa. O período médio de internação dos pacientes foi de 13 horas e meia após a extubação.

Ao receberem alta hospitalar os pacientes eram medicados com antibiótico (cefalexina 500mg um comprimido de $6 / 6$ horas por sete dias) e analgésico (dipirona 35 a 40 gotas de $4 / 4$ horas, se necessário).

Os pacientes retornaram à clínica para ativação do aparelho em média com 6 dias após o ato cirúrgico e neste momento iniciou-se a ativação do aparelho expansor, com quatro vezes $1 / 4$ de volta totalizando $1 \mathrm{~mm}$. Posteriormente preconizou-se duas vezes $1 / 4$ de volta de ativação por dia, uma

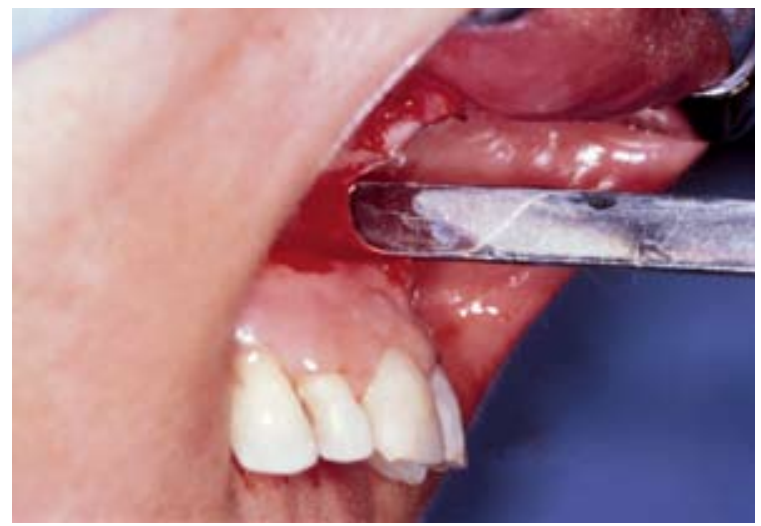

FIGURA 8 - 0steotomia na região da sutura inter-maxilar com cinzéis.

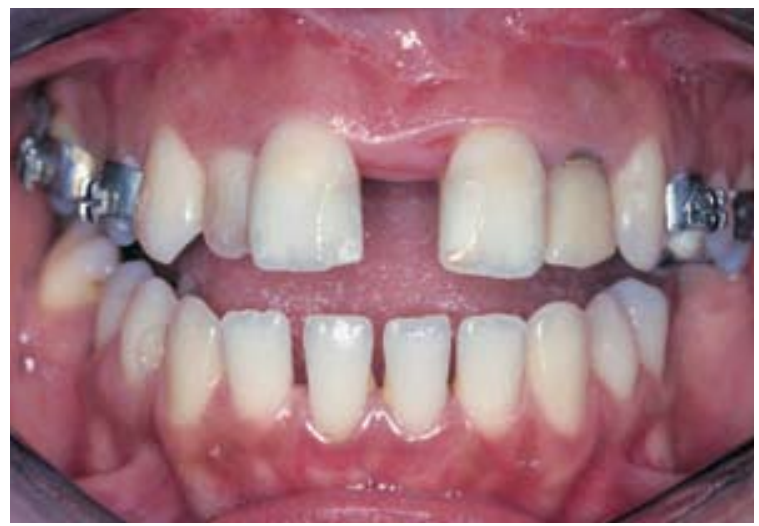

FIGURA 10 - Abertura conseguida após ativação do aparelho Hyrax, com 25 dias.

vez pela manhã e uma vez pela noite $(0,5 \mathrm{~mm} / \mathrm{dia})$ na primeira semana. Após a segunda semana era mudada a quantidade diária de expansão realizada, dependendo da sua idade e da quantidade de expansão requerida. Deste modo foi instituída um expansão lenta em grande parte dos pacientes após uma semana. Em alguns pacientes um repouso foi instituído entre as expansões, sendo realizada $1 / 4$ de volta com repouso de 24 horas. Instituiu-se $1 \mathrm{~mm}$ de sobrecorreção bilateralmente em todos os casos (Fig. 9, 10).

Durante o tratamento ortodôntico os pacientes passavam por avaliações clínicas e radiográficas (Fig. 11, 12, 13). Sendo que o período de análise para este estudo foi até a remoção dos aparelhos fixos (Fig. 14, 15). 

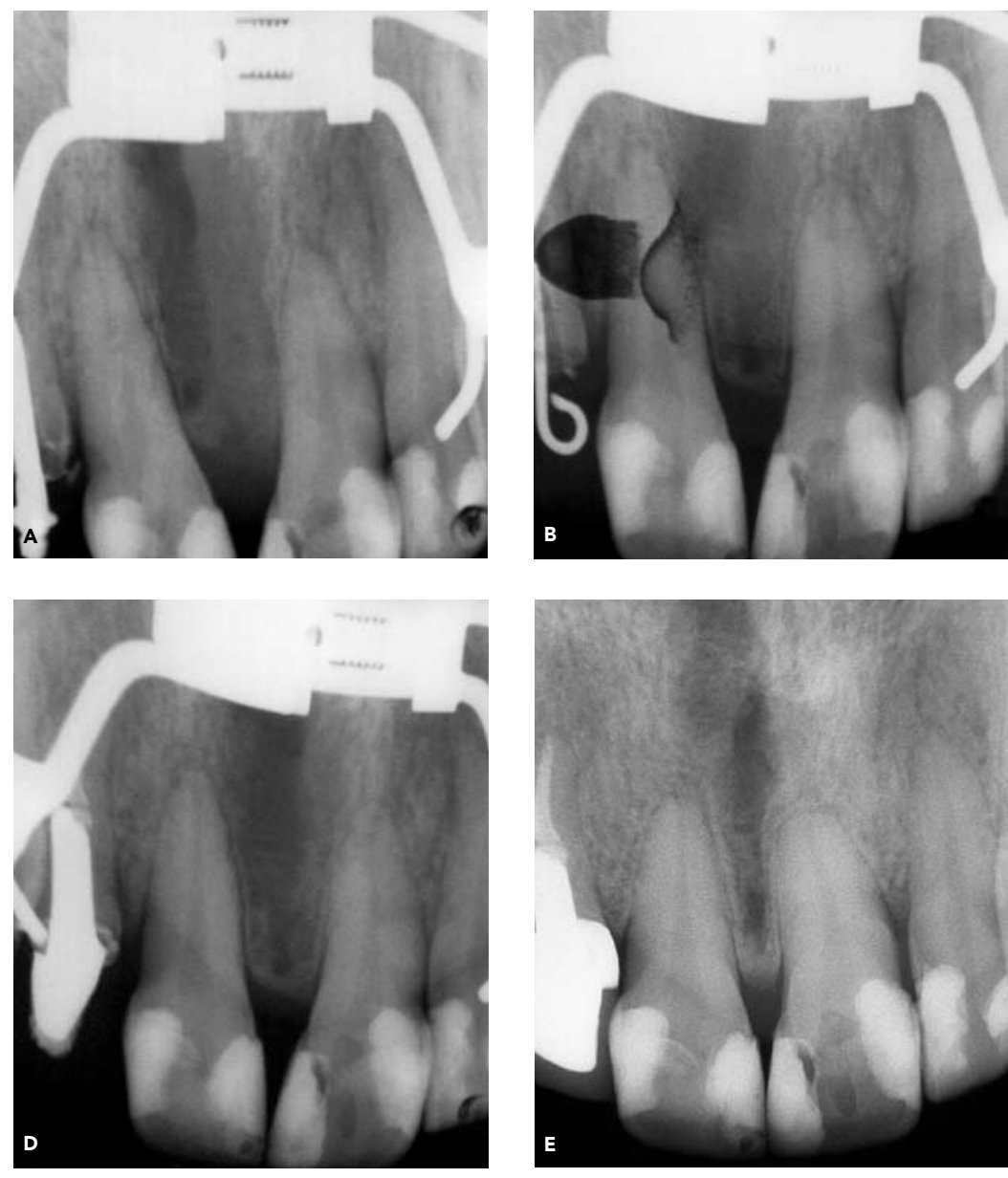

FIGURA 11 - Seqüência de radiografias periapicais pós-operatórias, mostrando o aumento da radiopacidade na região inter-maxilar desde a expansão até início de alinhamento e nivelamento.
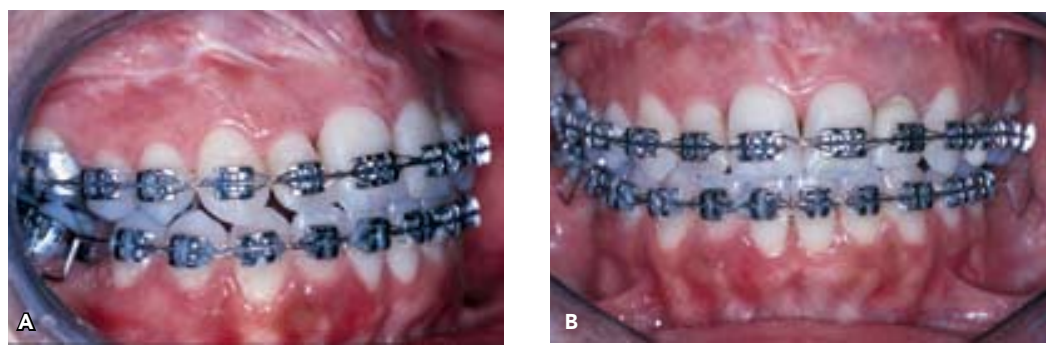

FIGURA 13 - Aspecto clínico durante o alinhamento e nivelamento após remoção do aparelho expansor.
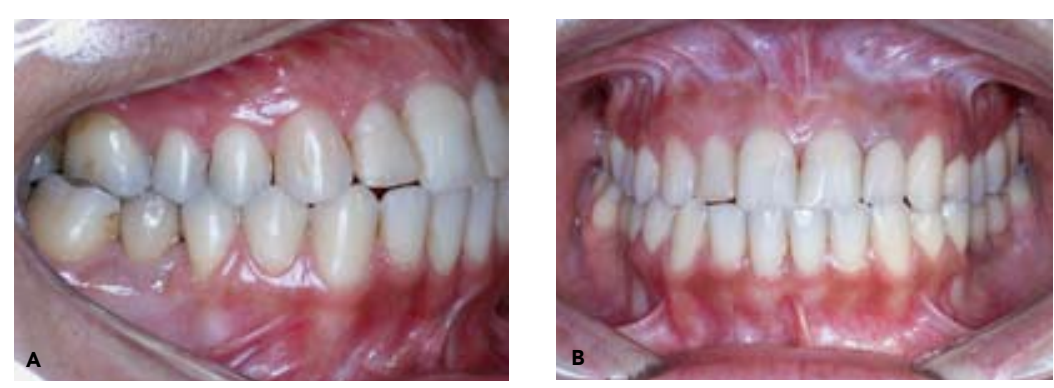

FIGURA 14 - Vista clínica após 23 meses após remoção do aparelho fixo.
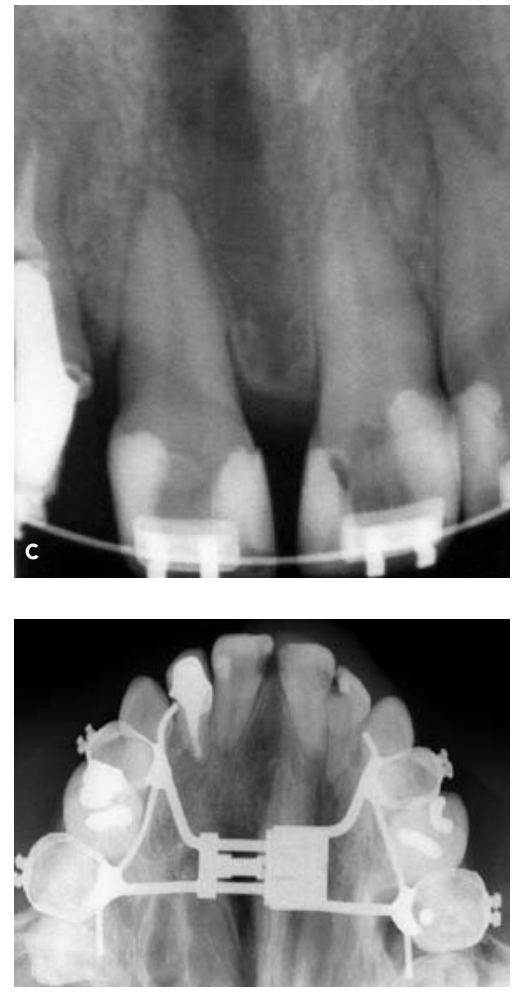

FIGURA 12 - Radiografia oclusal pós-operatória mostrando radiopacidade da região intermaxilar podendo indicar a remoção do expansor.
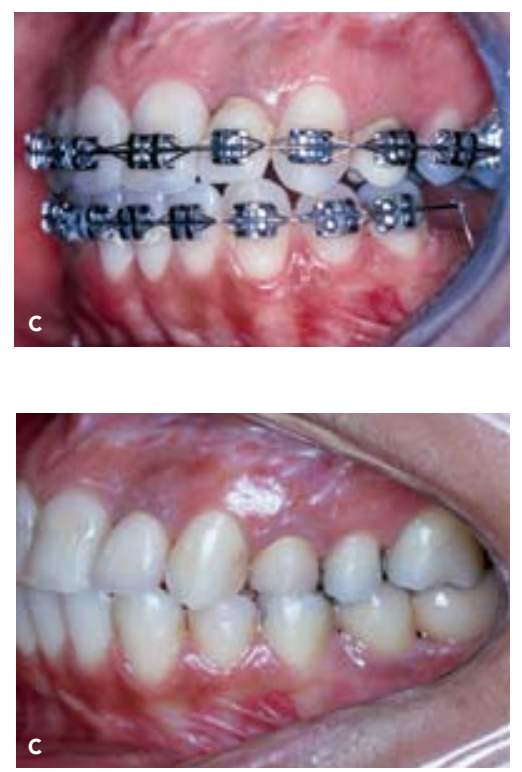


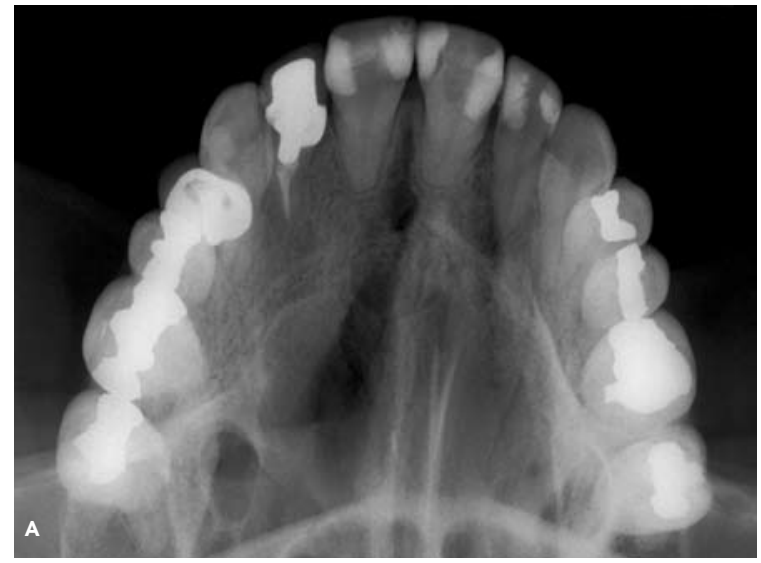

\section{RESULTADOS}

O padrão facial e o tipo de oclusão predominante foi de Classe II com 40\% dos casos, seguido de Classe I com 30\% dos pacientes, Classe I associada a laterognatismo com $20 \%$ e Classe I associada à face longa e a mordida aberta com $10 \%$ dos casos (Tab. 1).

Em três pacientes (30\%) havia sido tentada a expansão ortopédica através de expansores do tipo Haas. A média de idade destes pacientes era

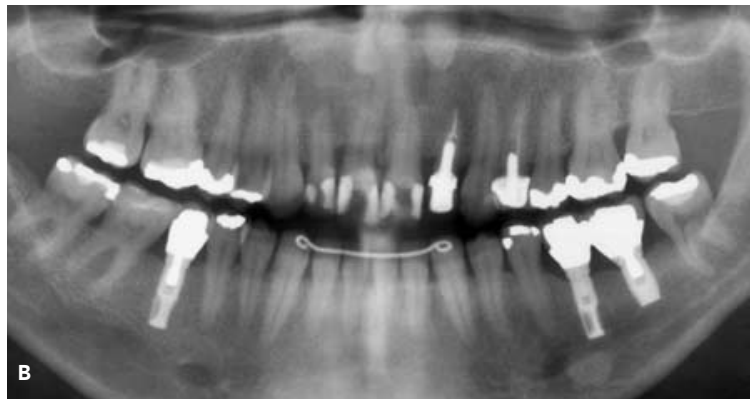

FIGURA 15 - Aspecto radiográfico 23 meses após remoção do aparelho fixo: A) tomada oclusal, B) tomada panorâmica.

de 19,8 anos (17,4 a 22,2 anos). As complicações observadas foram a necrose da mucosa palatina em dois pacientes e a inclinação para vestibular dos dentes de ancoragem em um paciente, além de grande desconforto relatado pelos mesmos durante a ativação do expansor (Tab. 1).

A única complicação observada durante o transoperatório foi a ocorrência de hemorragia em um paciente, que aconteceu durante finalização da osteotomia lateral da maxila, na região posterior.

Tabela 1 - Dados pessoais e referentes ao pré, trans e pós-operatório dos pacientes submetidos à ECAM.

\begin{tabular}{|c|c|c|c|c|c|c|c|}
\hline Paciente & Tipo de oclusão & Idade & $\begin{array}{l}\text { Tentativa de } \\
\text { expansão } \\
\text { ortopédica }\end{array}$ & $\begin{array}{l}\text { Complicações } \\
\text { da expansão } \\
\text { ortopédica }\end{array}$ & $\begin{array}{l}\text { Complicações } \\
\text { trans-operatórias }\end{array}$ & $\begin{array}{c}\text { Início da } \\
\text { ativação após } \\
\text { cirurgia }\end{array}$ & $\begin{array}{l}\text { Período total } \\
\text { de ativação }\end{array}$ \\
\hline 1 & Classe II & 25a. $5 \mathrm{~m}$ & Não & --- & Não & 4 dias & 23 dias \\
\hline 2 & Classe I & 17a. $4 \mathrm{~m}$ & Sim & Necrose palatina & Não & 5 dias & 18 dias \\
\hline 3 & Classe I & 22a. $8 \mathrm{~m}$ & Não & -- & Sim - Hemorragia & 4 dias & 35 dias \\
\hline 4 & $\begin{array}{c}\text { Classe I, } \\
\text { face longa, mordida } \\
\text { aberta }\end{array}$ & 19a. $5 \mathrm{~m}$ & Não & --- & Não & 4 dias & 19 dias \\
\hline 5 & Classe II & 17a. $4 \mathrm{~m}$. & Não & --- & Não & 8 dias & 29 dias \\
\hline 6 & Classe I & 24a. 8m. & Não & -- & Não & 7 dias & 25 dias \\
\hline 7 & Classe II & 41a. $11 \mathrm{~m}$. & Não & --- & Não & 5 dias & 73 dias \\
\hline 8 & $\begin{array}{c}\text { Classe I, } \\
\text { laterognatismo }\end{array}$ & 22a. $2 \mathrm{~m}$. & Sim & $\begin{array}{l}\text { Inclinação ves- } \\
\text { tibular dos dentes }\end{array}$ & Não & 7 dias & 12 dias \\
\hline 9 & Classe II & $24 a$. & Não & -- & Não & 4 dias & 20 dias \\
\hline 10 & $\begin{array}{c}\text { Classe I, } \\
\text { laterognatismo }\end{array}$ & 18a. $5 \mathrm{~m}$. & Sim & Necrose palatina & Não & 6 dias & 18 dias \\
\hline
\end{tabular}


Tabela 2 - Aumento inter-dentário conseguido logo após o final da expansão e a amplitude do total de abertura do aparelho expansor em cada paciente. Valores em milímetros.

\begin{tabular}{|c|c|c|c|c|c|c|c|}
\hline Paciente & $\begin{array}{l}\text { Distância Inter- } \\
\text { dentária }\end{array}$ & Canino & $1^{\circ}$ pré-molar & $2^{\circ}$ pré-molar & $1^{\circ}$ molar & $2^{\circ}$ molar & $\begin{array}{c}\text { Total de ativação } \\
\text { do expansor }\end{array}$ \\
\hline & Pré & 33,0 & 36,0 & 41,5 & 48,5 & 54,0 & \\
\hline \multirow[t]{3}{*}{1} & Pós & 39,0 & 43,0 & 48,5 & 55,0 & 61,0 & 11,0 \\
\hline & Diferença & 6,0 & 7,0 & 7,0 & 6,5 & 7,0 & \\
\hline & Pré & 30,0 & 33,5 & 37,0 & 39,0 & 41,0 & \\
\hline \multirow[t]{3}{*}{2} & Pós & 34,0 & 38,0 & 42,0 & 44,0 & 47,5 & 6,00 \\
\hline & Diferença & 4,0 & 4,5 & 5,0 & 6,0 & 6,5 & \\
\hline & Pré & 30,0 & 32,5 & --- & 40,0 & 48,0 & \\
\hline \multirow[t]{3}{*}{3} & Pós & 31,0 & 39,0 & --- & 46,0 & 54,0 & 7,50 \\
\hline & Diferença & 1,0 & 6,5 & --- & 6,0 & 6,0 & \\
\hline & Pré & 34,0 & 36,0 & 43,0 & 49,5 & 54,0 & \\
\hline \multirow[t]{3}{*}{4} & Pós & 39,0 & 41,0 & 43,0 & 53,5 & 59,0 & 9,50 \\
\hline & Diferença & 5,0 & 5,0 & 6,0 & 4,0 & 5,0 & \\
\hline & Pré & 31,0 & 32,0 & 39,0 & 48,0 & 51,0 & \\
\hline \multirow[t]{3}{*}{5} & Pós & 38,0 & 38,0 & 47,0 & 54,0 & 57,0 & 8,25 \\
\hline & Diferença & 7,0 & 6,0 & 8,0 & 6,0 & 6,0 & \\
\hline & Pré & 31,0 & 33,0 & 38,0 & 46,0 & 51,0 & \\
\hline \multirow[t]{3}{*}{6} & Pós & 37,0 & 40,0 & 45,0 & 52,0 & 55,0 & 10,50 \\
\hline & Diferença & 6,0 & 7,0 & 7,0 & 6,0 & 4,0 & \\
\hline & Pré & 30,0 & 38,0 & -- & 45,0 & -- & \\
\hline \multirow[t]{3}{*}{7} & Pós & 37,0 & 45,0 & --- & 52,0 & --- & 11,00 \\
\hline & Diferença & 7,0 & 7,0 & --- & 7,0 & --- & \\
\hline & Pré & 37,0 & 40,0 & 51,0 & 53,0 & 59,0 & \\
\hline \multirow[t]{3}{*}{8} & Pós & 40,0 & 45,0 & 54,0 & 59,0 & 62,0 & 7,0 \\
\hline & Diferença & 3,0 & 5,0 & 3,0 & 6,0 & 3,0 & \\
\hline & Pré & 32,5 & 33,0 & 45,0 & 46,0 & 53,0 & \\
\hline \multirow[t]{3}{*}{9} & Pós & 38,0 & 37,0 & 47,5 & 52,0 & 56,0 & 8,75 \\
\hline & Diferença & 5,5 & 4,0 & 2,5 & 6,0 & 3,0 & \\
\hline & Pré & 30,0 & 31,0 & 38,0 & 47,0 & 51,0 & \\
\hline \multirow[t]{2}{*}{10} & Pós & 34,0 & 36,0 & 42,0 & 51,0 & 54,0 & 3,0 \\
\hline & Diferença & 4,0 & 5,0 & 4,0 & 4,0 & 3,0 & \\
\hline
\end{tabular}

Esta foi sanada através da compressão com gaze (Tab. 1). O tempo necessário para a ativação foi de 43 dias em média (12 a 73 dias). Durante o período de ativação do expansor não foi verificada queixa de dor pelos pacientes (Tab. 1).

A média de expansão realizada foi de $8,65 \mathrm{~mm}$ (d.p. $\pm 3,39 \mathrm{~mm})(6,0$ a $11,0 \mathrm{~mm})$. Através das medidas inter-dentárias registradas no pré-operatório e no pós-operatório, logo após a expansão maxilar foi possível observar que o total de expansão realizada não corresponde ao aumento entre as distâncias inter-dentárias, sendo que este encontra-se 
Tabela 3 - Efeitos observados nos pacientes após o procedimento de ECAM.

\begin{tabular}{|c|c|c|c|c|c|c|}
\hline \multirow[t]{2}{*}{ Paciente } & \multicolumn{2}{|c|}{$\begin{array}{c}\text { Distância inter-processos } \\
\text { alares (mm) }\end{array}$} & \multirow[t]{2}{*}{$\begin{array}{l}\text { Verificação de formação } \\
\text { óssea radiograficamente }\end{array}$} & \multirow[t]{2}{*}{ Remoção do expansor } & \multirow[t]{2}{*}{$\begin{array}{l}\text { Fechamento do diaste- } \\
\text { ma inter-incisivo }\end{array}$} & \multirow[t]{2}{*}{$\begin{array}{l}\text { Melhora de respira- } \\
\text { ção nasal }\end{array}$} \\
\hline & Pré & 31,5 & & & & \\
\hline \multirow[t]{3}{*}{1} & Pós & 34,0 & 150 dias & 167 dias & 32 dias & Sim \\
\hline & Diferença & 2,5 & & & & \\
\hline & Pré & 20,5 & & & & \\
\hline \multirow[t]{3}{*}{2} & Pós & 29,5 & 92 dias & 133 dias & 35 dias & $\begin{array}{l}\text { Sem alteração } \\
\text { significante }\end{array}$ \\
\hline & Diferença & 9,0 & & & & \\
\hline & Pré & 23,5 & & & & \\
\hline \multirow[t]{3}{*}{3} & Pós & 32,0 & 98 dias & 128 dias & 40 dias & Sim \\
\hline & Diferença & 7,5 & & & & \\
\hline & Pré & 32,0 & & & & \\
\hline \multirow[t]{3}{*}{4} & Pós & 33,0 & 120 dias & 170 dias & Não avaliado & Sim \\
\hline & Diferença & 1,0 & & & & \\
\hline & Pré & 32,0 & & & & \\
\hline \multirow[t]{3}{*}{5} & Pós & 34,0 & 110 dias & 180 dias & 45 dias & $\begin{array}{l}\text { Sem alteração } \\
\text { significante }\end{array}$ \\
\hline & Diferença & 2,0 & & & & \\
\hline & Pré & 25,0 & & & & \\
\hline \multirow[t]{3}{*}{6} & Pós & 27,0 & 140 dias & 150 dias & 30 dias & $\begin{array}{l}\text { Sem alteração } \\
\text { significante }\end{array}$ \\
\hline & Diferença & 2,0 & & & & \\
\hline & Pré & 33,0 & & & & \\
\hline \multirow[t]{3}{*}{7} & Pós & 33,0 & 73 dias & 78 dias & Durante ativação & Sim \\
\hline & Diferença & 0,0 & & & & \\
\hline & Pré & 37,0 & & & & \\
\hline \multirow[t]{3}{*}{8} & Pós & 40,0 & 136 dias & 198 dias & 37 dias & $\begin{array}{l}\text { Sem alteração } \\
\text { significante }\end{array}$ \\
\hline & Diferença & 3,0 & & & & \\
\hline & Pré & 32,5 & & & & \\
\hline \multirow[t]{3}{*}{9} & Pós & 38,0 & 90 dias & 143 dias & 30 dias & Sim \\
\hline & Diferença & 5,5 & & & & \\
\hline & Pré & 30,0 & & & & \\
\hline \multirow[t]{2}{*}{10} & Pós & 34,0 & 83 dias & 190 dias & 42 dias & $\operatorname{Sim}$ \\
\hline & Diferença & 4,0 & & & & \\
\hline Média & & & 111,5 (73-150 dias) & 138 (78-198 dias) & 37,5 (30 a 45 dias) & $60 \%$ \\
\hline
\end{tabular}

inferior ao total de ativação do aparelho (Tab. 2).

$\mathrm{Na}$ avaliação da alteração entre os processos alares foi obtido um aumento médio de $4,75 \mathrm{~mm}$ (d.p. $\pm 3,71 \mathrm{~mm}$ ) (Tab. 3).

O período de neoformação óssea verificado através de tomadas radiográficas oclusais variou de
73 dias a 150 dias, com uma média de 111,5 dias (d.p. $\pm 38,5)$ (Tab. 3).

Para a indicação de remoção do aparelho expansor também foi realizada radiografia periapical dos incisivos centrais superiores. Quando presenciava-se a formação de lâmina dura ao 
redor dos ápices dos incisivos centrais superiores e a radiopacidade na região inter-incisiva era indicada a remoção do aparelho expansor. O período médio de remoção do expansor foi de 138 dias após o término da ativação (78 a 198 dias).

$\mathrm{Na}$ avaliação do fechamento do diastema inter-incisivo foi possível constatar que ocorreu uma inclinação da coroa dos incisivos centrais para a região medial em média após 37,5 dias (d.p. \pm 7,5) do final da expansão. Neste período os ápices radiculares ainda encontravam-se afastados.

A avaliação da melhora da respiração nasal foi realizada de maneira subjetiva em todos os pacientes. Seis pacientes $(60 \%)$ tiveram significante melhora da respiração nasal (Tab. 3).

Foi realizada análise estatística para verificação da significância das diferenças observadas entre

Tabela 4 - Análise de variância referente aos valores médios dos aumentos inter-dentários e do aparelho expansor. Valores em milímetros.

\begin{tabular}{|c|c|c|c|c|}
\hline \multicolumn{2}{|r|}{ Grupo } & & & d.p. \\
\hline \multicolumn{2}{|r|}{ Canino } & & & 2,01 \\
\hline \multicolumn{2}{|c|}{$1^{\circ}$ Pré-molar } & & & 2,23 \\
\hline \multicolumn{2}{|c|}{$2^{\circ}$ Pré-molar } & & & 1,99 \\
\hline \multicolumn{2}{|r|}{$1^{\circ}$ Molar } & & & 2,24 \\
\hline \multicolumn{2}{|r|}{$2^{\circ} \mathrm{molar}$} & & & 1,88 \\
\hline \multicolumn{2}{|r|}{ Expansor } & & & 3,39 \\
\hline \multicolumn{5}{|c|}{ Análise de variância } \\
\hline $\begin{array}{l}\text { Fonte de } \\
\text { variação }\end{array}$ & Soma dos quadrados & $\begin{array}{c}\text { Classe I } \\
\text { Laterognatismo }\end{array}$ & Quadrado médio & 'F' \\
\hline Entre grupos & 100,2651 & 5 & 20,05303 & 7,81474 \\
\hline Resíduo & 130,8687 & 51 & 2,566052 & \\
\hline Total & 231,1338 & 56 & & \\
\hline \multicolumn{3}{|c|}{ Significante em $5 \%$} & \multicolumn{2}{|c|}{ F crítico $(5 \%)=2,37$} \\
\hline \multicolumn{3}{|c|}{ Comparações individuais (Turkey Kramer) } & \multicolumn{2}{|c|}{ Significância } \\
\hline \multicolumn{3}{|c|}{ Canino $X 1^{\circ}$ pré } & \multicolumn{2}{|c|}{ n.s. } \\
\hline \multicolumn{3}{|c|}{ Canino $X 2^{\circ}$ pré } & \multicolumn{2}{|c|}{ n.s. } \\
\hline \multicolumn{3}{|c|}{ Canino $\mathrm{X} 1^{\circ}$ molar } & \multicolumn{2}{|c|}{ n.s. } \\
\hline \multicolumn{3}{|c|}{ Canino $X 2^{\circ}$ molar } & \multicolumn{2}{|c|}{ n.s. } \\
\hline \multicolumn{3}{|c|}{ Canino $\mathrm{X}$ expansor } & \multicolumn{2}{|c|}{$5 \%$} \\
\hline \multicolumn{3}{|c|}{$1^{\circ}$ pré $X 2^{\circ}$ pré } & \multicolumn{2}{|c|}{ n.s } \\
\hline \multicolumn{3}{|c|}{$1^{\circ}$ pré $X 1^{\circ}$ molar } & \multicolumn{2}{|c|}{ n.s } \\
\hline \multicolumn{3}{|c|}{$1^{\circ}$ pré $X 2^{\circ}$ molar } & \multicolumn{2}{|c|}{ n.s } \\
\hline \multicolumn{3}{|c|}{$1^{\circ}$ pré X expansor } & \multicolumn{2}{|c|}{$5 \%$} \\
\hline \multicolumn{3}{|c|}{$2^{\circ}$ pré $X 1^{\circ}$ molar } & \multicolumn{2}{|c|}{ n.s. } \\
\hline & $2^{\circ}$ pré $X$ & & & \\
\hline & $2^{\circ}$ pré $X \mathrm{e}$ & & & \\
\hline & $1^{\circ}$ molar $X$ & & & \\
\hline & $1^{\circ}$ molar $X$ & & & \\
\hline & $2^{\circ}$ molar $X$ & & & \\
\hline
\end{tabular}


Tabela 5 - Valores médios, desvio padrão e a significância da diferença encontrada na distância inter-processos alares. Valores em milímetros.

\begin{tabular}{ccc}
\hline $\begin{array}{c}\text { Distância inter-processos } \\
\text { alares }\end{array}$ & $\overline{\mathbf{X}}$ & d.p. \\
\hline Pré-operatório & 29,5 & 5,37 \\
Pós-operatório & 33,45 & 3,71 \\
Teste $t=-3,644$ & Significante em $5 \%$ & F crítico $(5 \%)=2,262$ \\
\hline
\end{tabular}

as medidas interdentárias e o total de ativação do expansor. $\mathrm{Na}$ comparação global entre as medidas pelo teste ANOVA a um critério, houve diferença significante entre os grupos, utilizando-se de fator crítico a $5 \%$. O aumento das medidas interdentárias e o total de ativação do expansor foram comparados individualmente entre si, pelo teste de Tukey Kramer. Os valores foram significantes quando o total de ativação do expansor foi comparado com a diferença inter-dentária conseguida em cada grupo. Quando a diferença interdentária foi comparada nos grupos dentários entre si não houve diferença significante (Tab. 4).

Pela análise estatística para verificação da significância das diferenças observadas entre as medidas no pré e pós-operatório da distância interprocessos alares observou-se, através do teste $t$ de Student, que houve diferença significante entre as medidas nos grupos examinados, utilizando-se fator crítico a 5\% (Tab. 5).

\section{DISCUSSÃO}

No presente estudo foram avaliados os resultados do tratamento por ECAM em dez pacientes. Dos pacientes tratados neste trabalho apenas quatro apresentavam idade inferior a 20 anos, porém todos eles já haviam passado da fase de crescimento maxilar ${ }^{12}$.

Timms e Vero ${ }^{51}$ acreditam que em todos os pacientes com idade inferior a 25 anos deve ser tentada a expansão ortopédica da maxila. Os autores afirmaram que, quanto maior a idade, maior é a necessidade de uma técnica cirúrgica mais extensa.
Muitos trabalhos relatam os riscos de falhas da expansão ortopédica, bem como o alto índice de recidiva deste procedimento em adultos $2,7,12,29,37,53,54$.

O desconforto durante a expansão ortopédica foi relatado por todos os pacientes com idade abaixo de 25 anos tratados por Alpern e Yurosko ${ }^{1}$. Sabe-se que existe um aumento dos movimentos ortodônticos com o aumento da idade ${ }^{7}$. Capelozza Filho et al. ${ }^{12}$ relataram que as falhas na expansão ortopédica da maxila em adultos podem chegar próximo a $30 \%$. Persson e Thilander ${ }^{38}$ verificaram, em estudos realizados em cadáveres, que a sinosteose da sutura intermaxilar começa entre 15 e 19 anos de idade e aumenta significantemente com a idade. Kraut ${ }^{27}$ relatou falha na ECAM em pacientes de 18 e 19 anos de idade, atribuindo-as à grande sinosteose da sutura intermaxilar. Neste sentido muitos autores acreditam que a ECAM deva ser indicada após os 15 anos $^{9}$.

As falhas relacionadas com a expansão ortopédica da maxila parecem estar acontecendo em fases mais precoces. Morselli ${ }^{35}$ relatou falhas de expansão ortopédica em pacientes de 8 e 14 anos de idade. No nosso estudo foi possível constatar falha da expansão ortopédica em três pacientes, com idades de 17,4 a 22,8 anos. Estas características somadas aos achados na literatura nos fazem acreditar que a maturidade esquelética dos pacientes está sendo atingida em períodos mais precoces.

Os pacientes que sofreram tentativa de expansão ortopédica permaneciam com grande receio para realizar o procedimento em casa. Porém, após a ativação, todos os pacientes nos relatavam que não realizariam o tratamento novamente se não fosse realizada a ECAM, devido a esta reduzir todo desconforto da expansão.

$\mathrm{Na}$ nossa avaliação pôde-se constatar que pacientes portadores de má oclusão Classe II foram os que mais apresentaram deficiência transversal da maxila, o que vem a ser diferente da maioria dos pacientes tratados por Betts et al. ${ }^{9}$ e Capelozza Filho et al. ${ }^{13}$ 
A técnica cirúrgica que envolve a liberação de todas as articulações da maxila é a preferida por diversas correntes $s^{4,8,9,25,27,35,36}$. Betts et al. ${ }^{9}$ afirmaram que a separação dos processos pterigóides deve ser realizada em todos os casos para que não haja prejuízo da expansão na região posterior, porque ao contrário da maxila o osso esfenóide é um osso único que possui dois processos que se articulam com cada osso maxilar. Outros acreditam que a osteotomia dos processos pterigóides não é necessária ${ }^{13,37,40}$.

A tentativa de se realizar técnicas conservadoras, que não utilizam osteotomia na sutura intermaxilar e liberação dos processos pterigóides, pode muitas vezes estar associada a falhas e desconforto durante a ativação, causando efeitos adversos nos dentes suportes, ferimento da mucosa palatina e a incapacidade de se atingir a quantidade ideal de expansão, sendo necessário o paciente ser submetido a novo procedimento cirúrgico para que se atinja o objetivo do tratamento $5,17,23,29,30,33,34$. Kennedy et al. ${ }^{25}$, através de estudo em macacos, concluíram que o pilar zigomático é o que oferece maior resistência à expansão maxilar, porém acreditam que para ocorrer o verdadeiro movimento basal da maxila todos os pilares devem ser seccionados, assim como a sutura intermaxilar.

A realização de osteotomias que envolvem diretamente o osso palatino, associadas a osteotomias na parede lateral de maxila, é preconizada por alguns autores ${ }^{32,37}$. Possuindo como desvantagem a necessidade de instalação do aparelho expansor após a cirurgia. $\mathrm{O}$ acesso desta técnica além de aumentar a morbidade do procedimento diminui significantemente o suprimento sangüíneo do osso, do ligamento periodontal e dos dentes, podendo estar associada muitas vezes a seqüelas vasculares ${ }^{15}$. Assim como $\mathrm{Kraut}^{27}$ acreditamos que a realização de osteotomias através do acesso palatino e pelo acesso vestibular seja uma técnica que deve ser levada em consideração em falhas da ECAM e quando se constatar uma espessa sinosteose na sutura intermaxilar.

Muitos autores atribuem como desvantagem deste procedimento, onde se realiza uma osteotomia tipo Le Fort I subtotal, a necessidade do mesmo ser realizado sob anestesia geral ${ }^{6,17,23,29,30,34}$. Sabemos que mesmo os procedimentos de ECAM que não se utilizam de osteotomia na sutura intermaxilar e nos processos pterigóides, realizados sob anestesia local, trazem desconforto aos pacientes durante o transoperatório e que acidentes podem acontecer, sendo muitos destes de difícil resolução quando o paciente estiver sob este tipo de anestesia.

Com os resultados obtidos neste trabalho foi possível constatar que a técnica utilizada nos proporcionou uma expansão de base óssea da maxila, amenizando o movimento pendular e inferior do complexo maxilar. Esta foi conseguida devido à osteotomia horizontal na parede lateral da maxila ser realizada paralelamente ao plano oclusal dos dentes superiores e à liberação de todas articulações da maxila $^{9,41}$. Para a realização de uma osteotomia horizontal paralela ao plano oclusal superior posterior é necessário que na região de pilar zigomático uma osteotomia vertical de aproximadamente $6 \mathrm{~mm}$ de comprimento seja realizada e para que se continue a osteotomia horizontal até a união do tuber da maxila com os processos pterigóides. A realização da osteotomia vertical também possibilita que a resistência fornecida pelo pilar zigomático durante a expansão seja diminuída, devido à possibilidade de se alargar esta osteotomia, para que durante a expansão uma resistência não seja criada pelo contato ósseo prematuro na área deste pilar. A espessura desta osteotomia deve ser um pouco menor que a metade da expansão requerida, assim permitindo a livre expansão da maxila bilateralmente ${ }^{9}$.

Corroborando com diversos autores $4,8,9,18,27,35,45$ acreditamos que a técnica a ser realizada para a ECAM seja a de uma osteotomia tipo Le Fort I subtotal. Sendo a parede medial do seio maxilar não totalmente envolvida. Já a osteotomia do septo nasal deve ficar reservada em casos de grandes atresias. Devido a não haver mudança da posição do septo nasal quando realizamos a ECAM bilate$\mathrm{ra}^{45}$, e sabendo que o septo é uma continuidade 
da sutura intermaxilar, realizamos a ECAM sem inclusão deste.

Outro procedimento utilizado para correção das deficiências transversais é a osteotomia tipo Le Fort I associada à segmentação da maxila. Muitos autores defendem a utilização deste procedimento quando o paciente possui uma deficiência transversal associada a uma discrepância sagital e/ou vertical da maxila ${ }^{3,39,52}$. Porém, a utilização desta técnica fornece pouca estabilidade pós-operatória gerando grandes recidivas, além de possuir maior morbidade que a ECAM ${ }^{15,52}$. A recidiva destes procedimentos pode variar de 20 a $49 \%{ }^{44}$.

Acreditamos, como Silverstein e Quinn ${ }^{48}$, que os procedimentos de osteotomia tipo Le Fort I com segmentação da maxila devam ser indicados em pacientes que possuam deficiência transversal moderada e com uma curva de Spee intensa, sendo desta maneira tratados com alinhamento e nivelamento segmentar e uma osteotomia tipo Le Fort I particulada.

A ECAM é uma técnica de fácil confecção, que apresenta pouca morbidade e uma alta estabilida$\mathrm{de}^{5,6,41,49}$. Bays, Greco e Hale ${ }^{5}$ verificaram a estabilidade da ECAM após três a cinco anos de finalizado o tratamento ortodôntico e conseguiram uma boa estabilidade dos segmentos sem nenhuma alteração significante após a remoção do aparelho até o período estudado. Estes resultados vem a somar com os verificados por nós, onde após uma média de 49 meses da expansão nenhum paciente apresentava complicações.

As técnicas cirúrgicas conservadoras para ECAM podem propiciar recidivas mais pronunciadas. Bays e Greco $^{6}$ avaliaram pacientes onde foram realizadas apenas osteotomias na parede lateral da maxila. A média de recidiva foi de $8,8 \%$ na região de canino, $1 \%$ na região de pré-molares e $7,7 \%$ na região de molares. Racey ${ }^{41}$ utilizou-se de técnica cirúrgica envolvendo todas as articulações da maxila e observou que nesta a quantidade de recidiva é minimizada.

Com relação aos movimentos da maxila, o late- ral é o que predomina durante a expansão maxi$\operatorname{lar}^{31,44}$. Betts et al. ${ }^{9}$ afirmaram que se for realizada uma osteotomia do tipo rampa na parede lateral da maxila, a maxila pode deslocar-se lateral e inferiormente, ocasionando uma mordida aberta anterior.

Conseqüentemente, este deslocamento inferior da maxila influencia na posição espacial da mandíbula que irá exibir uma rotação para inferior e para trás ${ }^{11,44}$. Isto pode induzir alterações cefalométricas, com aumento do ângulo do plano mandibular e do eixo Y de crescimento, bem como a altura facial ântero-inferior ${ }^{11,44}$.

No nosso estudo podemos afirmar, com base nos resultados verificados com a quantidade de expansão dentária comparada com o total de ativação do aparelho, que o osso maxilar teve um deslocamento lateral com movimento pendular minimizado. $\mathrm{Na}$ avaliação clínica dos pacientes constatamos que não houve nenhum caso de formação nem aumento da mordida aberta anterior.

O período médio de permanência hospitalar dos pacientes avaliados foi de 13 horas e meia, variando de duas horas e meia a 24 horas após a extubação, isto devido à utilização de drogas de metabolização e excreção rápida ${ }^{41,43}$.

Acreditamos que a anestesia geral seja a melhor escolha para a realização desta técnica, tendo em vista que o paciente irá ser submetido ao procedimento sem qualquer desconforto ou mesmo dor durante o trans-operatório. A segurança proporcionada por este tipo de anestesia é indiscutível no momento de um acidente trans-operatório. Esta também nos permite uma maior amplitude da cirurgia, caso seja necessária durante o transoperatório.

A metodologia empregada para a ativação do expansor maxilar tem sido bastante discutida. O período adequado para se iniciar a expansão maxilar após a cirurgia varia segundo os autores. Capelozza Filho et al. ${ }^{13}$ recomendam que a expansão deva ser iniciada de 48 a 72 horas, realizando 2/4 de voltas neste instante e prosseguindo com 
$1 / 4$ de volta pela manhã e $1 / 4$ à noite. Morselli ${ }^{35}$ recomenda que seja realizada a abertura do expansor 5 ou 6 vezes no momento da cirurgia, Betts et al. ${ }^{9}$ indicam o início da expansão maxilar após cinco dias da cirurgia e, em casos em que não se tiver certeza da perfeita liberação da maxila, a ativação durante o trans-operatório poderá ser realizada, retornando o aparelho à posição.

Ilizarov $^{22}$ demonstrou experimentalmente que um período de cicatrização de cinco dias permite que haja um cruzamento dos capilares na área de osteotomia, além de verificar que a expansão de 0,5 a $1 \mathrm{~mm}$ por dia não ultrapassa o potencial de suprimento sangüíneo. Desta maneira, concordamos que o início da expansão não deva ocorrer antes do quinto dia após a cirurgia.

A metodologia de ativação empregada em nossos pacientes variou dependendo da idade, da maturação esquelética e da quantidade de expansão requerida. A expansão lenta foi imposta sempre após uma semana de expansão, através de duas vezes $1 / 4$ de volta por dia. A expansão lenta foi realizada instituindo-se $1 / 4$ de volta por dia com descanso de 24 horas.

Tem-se verificado que a expansão lenta da maxila pode aumentar movimentos ortodônticos, porém a força de tensão nos elementos da sutura, inicialmente é diminuída. O que permite uma resposta fisiológica mais tolerável desta região. Com a manutenção da integridade dos tecidos durante expansão, possibilita-se maior estabilidade e menor recidiva durante a reorganização do complexo maxilar ${ }^{6,21}$.

Levando em consideração os nossos resultados acreditamos que a expansão lenta possa ser utilizada na ECAM desde que se realize uma osteotomia tipo Le Fort I subtotal. Em nenhum dos nossos casos foi observado movimento ortodôntico através da inclinação vestibular dos dentes de ancoragem. Porém acreditamos que a metodologia aplicada neste estudo pode aumentar a resistência à expansão, principalmente nos casos onde não tenha sido realizada uma osteotomia tipo Le Fort I subtotal. Por isso, no momento acreditamos que, em casos que requerem grande quantidade de expansão, a metodologia aplicada deva ser através da expansão rápida, sendo instituído um repouso de 5 a 7 dias a cada $5 \mathrm{~mm}$ de expansão conseguida.

Uma característica clínica que podemos levar em consideração, para saber se a metodologia aplicada para a expansão está dentro dos padrões de regeneração do paciente, é o processo de desqueratinização da gengiva marginal na face mesial dos incisivos centrais. Este é simplesmente um tecido imaturo queratinizado, onde o rápido movimento dentário excedeu a capacidade da gengiva maturálo. Quando identificarmos uma área eritematosa próxima à face mesial do incisivo central, acreditamos que um repouso deva ser instituído.

O aparelho utilizado em todos pacientes avaliados neste estudo foi o expansor dento-suportado $\operatorname{Hyrax}^{33,40,46}$, devido a este facilitar a higiene pósoperatória, além da incapacidade de gerar lesões necróticas na mucosa palatina, como em casos de ECAM relatados ${ }^{13,29,30}$, o que pode vir a diminuir o suprimento sangüíneo dos segmentos maxilares expandidos pela compressão das artérias palatinas, podendo causar seqüelas vasculares graves ${ }^{15}$.

O aumento das distâncias interdentárias mostrou-se inferior ao do aparelho expansor, este efeito é provocado pelo movimento pendular dos ossos maxilares quando da expansão $0^{9,41}$.

$\mathrm{Na}$ análise estatística, quando a diferença inter-dentária foi comparada entre os grupos dentários, esta não foi significante, ou seja semelhante. Nestes grupos existia tanto dentes que forneciam ancoragem ao aparelho expansor e dentes fora da ancoragem, o que nos vem salientar que houve uma movimentação da base óssea e não somente do dente de ancoragem.

As alterações estéticas proporcionadas foram principalmente das distâncias entre os processos alares, visualizadas nos pacientes jovens e em mulheres. Apesar das diferenças observadas no pré e pós-operatório terem sido significantes, 
acreditamos que este aumento não está ligado diretamente à expansão, já que este aumento não foi proporcional à quantidade de expansão. Sabe-se que o estreitamento da base nasal é uma alteração de tecido mole que pode estar associada à atresia transversal da maxila ${ }^{9}$, o que permite um pequeno aumento da distância inter-processos alares ${ }^{9}$.

Muitos autores não recomendam qualquer procedimento a nível de processos alares ${ }^{13,45}$. Porém, existem correntes que recomendam a sutura da cartilagem alar para se prevenir o aumento da base nasal ${ }^{9,18}$. Acreditamos, assim como Epker, Fish e Paulus ${ }^{16}$ e Capelozza Filho et al. ${ }^{13}$, que as alterações de base nasal estão mais associadas com os procedimentos para correção de discrepâncias sagitais e/ou verticais de maxila, porém julgamos a partir dos resultados aqui encontrados que a sutura de base alar seja realizada de forma preventiva nos procedimentos de ECAM.

A maioria das vezes indica-se que o aparelho deva ser removido após três meses do final da expansão ${ }^{29,33,36,40}$. Porém, Halazonetis, Katsavrias e Spyropoulos ${ }^{19}$ demonstraram que após quatro meses não há uma adaptação dos tecidos moles circunjacentes e que a pressão causada pela bochecha é capaz de implicar na ocorrência de recidivas. Nos pacientes avaliados neste estudo a remoção do aparelho se deu quando foi verificada radiograficamente uma radiopacidade na região de sutura intermaxilar compatível com neoformação óssea local.

O fechamento do diastema inter-incisivo ocorre devido ao não seccionamento das fibras gengivais que ligam um dente ao outro. Estas são estiradas no momento da expansão e devido ao fato de manterem características de elasticidade, levam à mesialização dos incisivos centrais após o término da ativação ${ }^{9,11}$, ocorrendo em média neste estudo após 37 dias.

Alguns estudos relacionam o estreitamento do arco superior com o aumento da resistência à respiração nasal ${ }^{42}$. Sabemos, a partir do estudo de Ramadan ${ }^{42}$ realizado em coelhos, que o crescimento maxilar está diretamente ligado com a respiração nasal. Inúmeros são os estudos que relatam melhora da respiração nasal com aumento da cavidade nasal após a expansão maxilar, seja esta ortopedicamente ou cirurgicamente assistida ${ }^{33,45}$.

A rinometria é uma exame que pode determinar a resistência da via aérea nasal, caso esta exista, e o volume da cavidade nasal. Hahn et al. ${ }^{20}$, utilizando a rinometria acústica, verificaram um aumento do volume da cavidade nasal em 100\% dos indivíduos submetidos à expansão rápida da maxila.

Em nosso estudo avaliamos alterações da respiração nasal de maneira subjetiva. Assim 60\% dos pacientes relataram melhora na respiração através do nariz, somando desta forma a outros estudos $^{33,45}$.

\section{CONCLUSÕES}

Com base no tratamento de pacientes por meio da técnica de ECAM, podemos concluir que:

- Este foi um procedimento eficiente, com mínimas complicações;

- A técnica cirúrgica utilizada proporcionou adequado auxílio para a correção das deficiências transversais, com mínima morbidade;

- A metodologia utilizada para a ativação não deve ser tida como regra em todos os pacientes;

- Houve diferença estatisticamente significante entre os aumentos inter-dentários e o total de ativação do expansor $(p<0,05)$. Não houve diferença significante no aumento entre os grupos dentários;

- Houve um aumento entre os processos alares de $4,75 \mathrm{~mm}$ em média, estatisticamente significante $(\mathrm{p}<0,05)$;

- A remoção do aparelho expansor ocorreu 138 dias em média após o término da ativação;

- O fechamento parcial do diastema inter-incisivos ocorreu 37,5 dias em média após o término da expansão;

- A maioria dos pacientes (60\%) relatou melhora na respiração nasal.

Enviado em: Outubro de 2004 Revisado e aceito: Março de 2005 


\title{
Clinical evaluation of surgically assisted maxillary expansion (SAME)
}

\begin{abstract}
Aim: clinical evaluation of surgically assisted maxillary expansion. Methods: the present study evaluated 10 patients who underwent surgically assisted maxillary expansion. The efficacy of the surgical procedure helping transverse maxillary expansion given by the Hyrax, expansion stability, post-operatory discomfort during the activation of the device, the quantity and quality of the expansion achieved, the age of the patients, nasal base alteration, and nasal breathing were analyzed. Results and Conclusions: from the results, it was possible to observe that surgically assisted maxillary expansion is an efficient and stable treatment, which offers functional changes and minimal aesthetic alterations.
\end{abstract}

Key words: Maxillary expansion. Surgically assisted maxillary expansion. Transverse maxillary deficiency.

\section{REFERÊNCIAS}

1. ALPERN, M. C.; YUROSKO, J. J. Rapid palatal expansion in adults: with and without surgery. Angle Orthod, Appleton, v. 57, no. 3 , p. $245-263$, July 1987.

2. BARBER, A. F.; SIMS, M. R. Rapid maxillary expansion and external root resorption in man: a scanning microscope study. Am J Orthod, St. Louis, v. 79, no. 6, p. 630-652, June 1981

3. BAILEY, L. J.; WHITE, R. P.; PROFFIT, W. R.; TURVEY, T. A. Segmental Le Fort I osteotomy for management of transverse maxillary deficiency. J Oral Maxillofac Surg, Philadelphia, v. 55, no. 7, p. 728-731, July 1997.

4. BANNING, L. M.; GERARD, N.; STEINBERG, B. J.; BOGDANO$F F$, E. Treatment of transverse maxillary deficiency with emphasis on surgically assisted-rapid maxillary expansion. Compend Contin Educ Dent, Lawrenceville, v. 17, no. 2, p. 170-178, Feb. 1996

5. BAYS, R. A.; GRECO, J. M.; HALE, R. G. A Long term stability of surgically assisted rapid palatal expansion (abstrat 1498). J Dent Res, Chicago, v. 69, p. 296, 1990. Special issue.

6. BAYS, R. A.; GRECO, J. M. Surgically assisted rapid palatal expansion: an outpatient technique with long-term stability. J Oral Maxillofac Surg, Philadelphia, v. 50, no. 2, p. 110-113, Feb. 1992.

7. BELL, R. A. A review of maxillary expansion in relation to rate of expansion and patient's age. Am J Orthod, St. Louis, v. 81 no. 1, p. 32-37, Jan. 1982.

8. BELL, W. H.; EPKER, B. N. Surgical-orthodontic expansion of the maxilla. Am J Orthod, St. Louis, v. 70, no. 5, p. 517-528, Nov. 1976.

9. BETTS, N. J. et al. Diagnosis and treatment of transverse maxillary deficiency. Int J Adult Orthod Orthognath Surg, Chicago, v. 10, no. 2, p. 75-96, 1995

10. CAPELOZZA FILHO, L.; SILVA FILHO, O. G. Expansão rápida da maxila: considerações gerais e aplicação clínica. Parte I. R Dental Press Ortodon Ortop Maxilar, Maringá, v. 2, n. 3, p. 88-104, maio/junho, 1997a.

11. CAPELOZZA FILHO, L.; SILVA FILHO, O. G. Expansão rápida da maxila: considerações gerais e aplicação clínica. Parte II. R Dental Press Ortodon Ortop Maxilar, Maringá, v. 2, n. 4, p. 86-108, jul./ ago. 1997b.

12. CAPELOZZA FILHO, L.; CARDOSO NETO, J.; SILVA FILHO, O. G.; URSI, W. J. S. Non-surgically assisted rapid maxillary expansion in adults. Int J Adult Orthodon Orthognath Surg, Chicago, v. 11, no 1, p. 57-66, 1996

13. CAPELOZZA FILHO, L. et al. Expansão rápida da maxila cirurgicamente assistida. Ortodontia, São Paulo, v. 27, n. 1, p. 21-30, jan./abr. 1994.

14. CISTULLI, P. A.; RICHARDS, G. N.; PALMISANO, R. G.; BERTHON-JONES, M.; SULLIVAN, C. E. Influence of maxillary constriction on nasal resistance and sleep apnea severity in pa- tients with Marfan's syndrome. Chest, Chicago, v. 110, no. 5 , p. 1184-1188, Nov. 1996

15. EPKER, B. N. Vascular considerations in orthognathic surgery. J Oral Surg, Chicago, v. 57, no. 5, p. 473-478, May 1984

16. EPKER, B. N.; FISH, L. C.; PAULUS, P. J. The surgical-orthodontic correction of maxillary deficiency. J Oral Surg, Chicago, v. 46 no. 2, p. 171-205, Aug. 1978.

17. GLASSMAN, A. S.; NAHIGIAN, S. J.: MEDWAY, J. M.; ARONOWIRTZ, H. I. Conservative surgical orthodontic adult rapid palatal expansion: sixteen cases. Am J Orthod, St. Louis, v. 86 no. 3, p. 207-213, Sept. 1984.

18. GONÇALES, E. S.; POLIDO, W. D. Tratamento ortodôntico-cirúrgico de deficiência transversal de maxila: conceitos para o cirurgião bucomaxilofacial e relato de caso. Revista Inst Ciênc Saúde, São Paulo, v. 16, n. 1, p. 56-59, jan./jun. 1998.

19. HALAZONETIS, D. J.; KATSAVRIAS, E.; SPYROPOULOS, M $N$. Changes in cheek pressure following rapid maxillary expansion. Eur J Orthod, Oxford, v. 16, no. 4, p. 295-300, Aug. 1994.

20. HAHN, L. et al. Avaliação do volume da cavidade nasal antes e após a expansão rápida da maxila por meio da rinometria acústica. Ortodontia Gaúcha, Porto Alegre, v. 3, n. 2, jul./dez. 1999.

21. HICKS, E. P. Slow maxillary expansion: A clinical study of the skeletal versus dental response to low-magnitude force. Am J Orthod, St. Louis, v. 73, no. 2, p. 121-141, Feb. 1978.

22. ILIZAROV, G. A. Clinical applications of tension-stress effect for limb lengthening. Clin Orthop Relat Res, Philadelphia, v. 250, p. 8-26, Jan. 1990

23. KABAN, L. B. Surgical orthodontic correction of transverse maxillary deficiency: a simplified approach, discussion. Plast Reconstr Surg, Baltimore, v. 73, no. 1, p. 62-68, Jan. 1984

24. KELLY, J. E.; HARVEY, C. R. An assessment of the occlusion of the teeth of youths 12-17 year. Vital HealthStat, Hyattsville, no. 162 , p. 1-65, Feb. 1977.

25. KENNEDY, J. W. et al. Osteotomy as an adjunct to rapid maxillary expansion. Am J Orthod, St. Louis, v. 70, no. 2, p. 123-137, Aug. 1976.

26. KOBLAN, P. M.; CAPUANO, M.; PANZER, R. Correction of posterior crossbite. Using surgically assisted rapid palatal expansion technique. Pediatr Dent, Chicago, v. 63, no. 2, p. 40-44, Feb. 1997.

27. KRAUT, R. A. Surgically assisted rapid maxillary expansion by opening the midpalatal suture. J Oral Maxillofac Surg, Philadelphia, v. 42, no. 10, p. 651-655, Oct. 1984.

28. LANG FORD, S. R.; SIMS, M. R. Root surface resorption repair and periodontal attachment following rapid maxillary expansion in man. Am J Orthod, St. Louis, v. 81, no. 2, p. 108-115, Feb. 1982.

29. LEHMAN, J. A.; HAAS, A. J. Surgical-orthodontic correction of transverse maxillary deficiency. Clin Plastic Surgery, Philadelphia, v. 16 , no. 4, p. 749-755, Oct. 1989. 
30. LEHMAN, J. A.: HAAS, A. J.; HAAS, D. G. Surgical-orthodontic correction of transverse maxillary deficiency: a simplified approach. J Plasic Reconstr Surg, Philadelphia, v. 73, no. 1, p. 62-68, Jan. 1984.

31. LINDER-ARONSON, S.; LINDGREN, J. The skeletal and dental effects of rapid maxillary expansion. Br J Orthod, Oxford, v. 6, p. 25-29, 1979.

32. LINES, P. A. Adult rapid maxillary expansion with corticotomy. Am J Orthod, St. Louis, v. 67, no. 1, p. 44-56, Jan. 1975.

33. MANGANELLO, L.C.; CAPPELETTE, M. Tratamento cirúrgico de pacientes com palato ogival e com obstrução nasal. Rev Assoc Paul Cir Dent, São Paulo, v. 50, n. 1, p. 79-81, jan./fev. 1996.

34. MESSER, E. J.; BOLLINGER, T. E.; KELLER, J. J. Surgical-mechanical maxillary expansion. Quintessence Int, Berlin, v. 10, no. 8, p. 13-16, 1979.

35. MORSELLI, P. G. Surgical maxillary expansion: a new minimally invasive technique. J Craniomaxillofac Surg, Edinburg, v. 25, no. 2, p. 80-84, Apr. 1997.

36. MOSSAZ, C. F.; BYLOFF, F. K.; RICHTER, M. Unilateral and bilateral corticotomes for correction of maxillary transverse discrepancies. Eur J Orthod, Oxford, v. 14, no. 2, p. 110-116, Apr. 1992.

37. NORTHWAY, W. M.; MEADE JR., J. B. Surgically assisted rapid maxillary expansion: a comparison of technique, response, and stability. Angle Orthod, Appleton, v. 67, no. 4, p. 309-320, 1997.

38. PERSSON, M.; THILANDER, B. Palatal suture closure in man from 15-35 years of age. Am J Orthod, St. Louis, v. 72, no. 1, p. 42-52, July 1977.

39. PHILLIPS, C.; MEDLAND, W.; FIELDS, H. W.; PROFFIT, W. R.; WHITE, R. P. Stability of surgical maxillary expansion. Int J Adult Orthodon Orthognath Surg, Chicago, v. 7, no. 3, p.139-146, 1992.

40. POGREL, M. A.; KABAN, L. B.; VARGERVIK, K.; BAUMRIND, S. Surgically assisted rapid maxillary expansion in adults. Int J Adult Orthodon Orthognath Surg, Chicago, v. 7, no. 1, p. 37-41, 1992.

41. RACEY, G. L. Surgically assisted rapid palatal expansion: an outpatient technique with long-term stability. J Oral Maxillofac Surg, Philadelphia, v. 50, p.114-115, 1992.

42. RAMADAN, M. F. Effect of experimental nasal obstruction on growth of alveolar arch. Arch Otolaryngol, Chicago, v. 110, p. 566-570, Sept. 1984.

43. RIBEIRO JR., P. D.; PADOVAN, L. E. M.; SILVA, O. L.; NARY FI$\mathrm{LHO}, \mathrm{H}$. Expansão cirurgicamente assistida da maxila realizada através de anestesia geral ambulatorial. In: JORNADA ACADÊMICA DE ARAÇATUBA "PROF. TAKEO ADHEMAR FURUSE", 18.,1998, Araçatuba. Anais...Araçatuba: UNESP, 1998. p. 37.

44. SANDIKÇIOGLU, M.; HAZAR, S. Skeletal and dental changes after maxillary expansion in the mixed dentition. Am J Orthod Dentofacial Orthop, St. Louis, v.111, no. 3, p. 321-327, Mar. 1997.

45. SCHWARZ, G. M.; THRASH, W. J.; BYRD, D. L.; JACOBS, J. D. Tomography assessment of nasal septal changes following surgical-orthodontic rapid maxillary expansion. Am J Orthod, St. Louis, v. 87, no. 1, p. 39-45, 1985.

46. SHETTY, V.; CARDID, J. M.; CAPUTO, A. A. et. al. Biomechanical rationale for surgical-orthodontic expansion of adult maxila. J Oral Maxillofac Surg, Philadelphia, v. 52, p. 742-749, 1994.

47. SILVA FILHO, O.; FREITAS, S. F.; CAVASSAN, A. O. Prevalência de oclusão normal e maloclusão em escolares da cidade de Bauru (São Paulo): part. I relação sagital. Rev Odontol USP, São Paulo, v. 4, n. 2, p. 130-137, abr./ jun. 1990.

48. SILVERSTEIN, K.; QUINN, P. D. Surgically-assisted rapid palatal expansion for management of transverse maxillary deficiency. J Oral Maxillofac Surg, Philadelphia, v. 55, p. 725-727, 1997.

49. STRÖMBERG, C.; HOLM, J. Surgically assisted, rapid maxillary expansion in adults. A retrospective long-term follow-up study. J Craniomaxillofac Surg, Edinburgh, v. 23, no. 4, p. 222-227, Aug. 1995.

50. TIMMS, D. Rapid maxillary expansion in the treatment of nocturnal enuresis. Angle Orthod, Appleton, v. 60, no. 3, p. 229-233, Nov. 1989.
51. TIMMS, D. J.; VERO, D. The relationship of rapid maxillary expansion to surgery with special reference to midpalatal synostosis. Br J Oral Surg, Edinburgh, v. 19, no. 3, p.180-196, 1981.

52. TURVEY, T. A. Maxillary expansion: a surgical technique based on surgical-orthodontic treatment objectives and anatomical considerations. J Maxilofac Surg, Stuttgart, v. 13, no. 2, p. 51-58, Apr. 1985.

53. WERTZ, R. A. Rapid expansion of the maxillary dental arch and nasal cavity by opening the mid-palatal suture. Angle Orthod, Appleton, v. 31, p. 73-90, 1961.

54. WERTZ, R. A. Skeletal and dental changes accompanying rapid midpalatal suture opening. Am J Orothod, St. Louis, v. 58, no. 2, p. 14-66, July 1970.
Endereço para correspondência

Paulo Domingos Ribeiro Junior

Rua Henrinque Savi, 5-63 - Vila Nova Universitária

Bauru/SP

CEP: 17.012-205

E-mail: paulodrj@aol.com 